\title{
Attention Deficit Hyperactivity Disorder Among School Children in Port Harcourt, Nigeria
}

\author{
Edward Achinike Daniel Alikor, Angela Ine Frank-Briggs, Boma Alali Ngozi Okoh*
}

Department of Paediatrics, University of Port Harcourt Teaching Hospital, Port Harcourt, Rivers State, Nigeria

Email address:

bomadatown@yahoo.com (B. A. N. Okoh)

\section{To cite this article:}

Edward Achinike Daniel Alikor, Angela Ine Frank-Briggs, Boma Alali Ngozi Okoh. Attention Deficit Hyperactivity Disorder Among School Children in Port Harcourt, Nigeria. American Journal of Psychiatry and Neuroscience. Vol. 3, No. 2, 2015, pp. 23-29.

doi: 10.11648/j.ajpn.20150302.12

\begin{abstract}
Attention Deficit Hyperactivity Disorder (ADHD) is the most common neurobehavioral disorder of childhood and one of the most prevalent chronic health conditions affecting school-aged children. With varying prevalence rates around the world, this study seeks to determine the prevalence of ADHD in primary school children in Port Harcourt, Southern Nigeria. It was a school - based descriptive cross sectional study using the Vanderbilt ADHD Diagnostic Teacher Rating Scale. A two staged stratified sampling technique was used to recruit pupils aged $4-18$ years from four selected primary schools. A total of 884 pupils were studied, consisting of 452 (51.1\%) males and 432 (48.9\%) females. Seven (0.8\%) had ADHD, out of which 6 $(85.7 \%)$ had predominantly inattentive, $2(28.6 \%)$ had predominantly hyperactive-impulsive and $1(14.3 \%)$ had the combined subtype. Four ( $0.9 \%)$ out of 432 females compared to $3(0.7 \%)$ out of 452 males had ADHD ( $p=0.475)$. Six (1.2\%) out of the 483 pupils equal to or above 10 years of age had ADHD compared to $1(0.2 \%)$ out of the 401 pupils less than 10 years of age ( $\mathrm{p}=0.098$ ). Oppositional \& Conduct disorders and Anxiety / Depression were found to be more prevalent in children with ADHD (42.9\% vs. $16.3 \%$ and $28.6 \%$ vs. $10.5 \%$ respectively). The study showed that ADHD does occur in children in Southern Nigeria and is associated with other psychiatric co-morbidities as in other parts of the world.
\end{abstract}

Keywords: Attention Deficit Hyperactivity Disorder, Inattention, Impulsive, School Children, Nigeria

\section{Introduction}

Attention Deficit Hyperactivity Disorder (ADHD) is a neurocognitive behavioural developmental disorder characterized by a persistent pattern of inattention and / or hyperactivity and impulsivity.[1] The 4th edition of the American Psychiatric Association's Diagnostic and Statistical Manual (DSM-IV) criteria state that the behavior must be developmentally inappropriate, begin before age 7 years, be present for at least 6 months, be present in 2 or more settings, and not be secondary to another disorder.[1] The new $5^{\text {th }}$ edition (DSM-5) however states that the symptoms can begin before 12 years, and for adults and adolescents age 17 or older, only 5 symptoms are needed instead of the 6 needed for younger children.[2] The three subtypes include the predominantly inattentive, predominantly hyperactiveimpulsive, and combined subtypes. It is the most common neurobehavioral disorder of childhood and one of the most prevalent chronic health conditions affecting school-aged children.[3] The aetiology of ADHD is unclear as no single factor determines the expression of ADHD although multiple factors have been implicated. [3] ADHD is more prevalent in boys than girls. [1]

Varying prevalence rates of ADHD have been reported in different regions around the world, ranging from $1-20 \%$. [4] The reasons for the different prevalence rates may be the differing sampling and testing techniques. Polanczyk et al [4] estimated the ADHD worldwide-pooled prevalence to be $5.29 \%$ in a Systematic Review and Metaregression Analysis. In a more recent updated Systematic Review and Metaregression Analysis, Polanczyk et al [5] concluded that there was no evidence to suggest an increase in the number of children in the community who meet criteria for ADHD when standardized diagnostic procedures are followed. Another meta - analytic review [6] suggested that the prevalence of DSM-IV ADHD is similar, whether ADHD is defined by parent ratings, teacher ratings, or a best estimate diagnostic procedure in children and adolescents (5.9-7.1\%), 
or by self-report measures in young adults $(5.0 \%)$. In their study, analyses of diagnostic subtypes indicated that the predominantly inattentive type is the most common subtype in the population, but individuals with the combined type are more likely to be referred for clinical services. Very few studies on ADHD among school children in Nigeria have been conducted among which are studies from Benin [7] and Osun[8] which revealed prevalence rates of $7.6 \%$ and $8.7 \%$ respectively.

Generally, affected children have difficulty in sustaining attention in tasks and play, are easily distracted, forgetful, are unable to stay still and often appear to be on the go. They therefore commonly experience academic underachievement, problems with interpersonal relationships with family members and peers, and low self-esteem. [7] If left untreated, ADHD could increase the risk for delinquency and substance abuse, particularly in the older adolescents. [9] ADHD also frequently co-occurs with other emotional, behavioral, language, and learning disorders. [3]

Although ADHD is the most extensively studied mental disorder of childhood [3] very few studies have been conducted on this important disabling disorder in Nigeria, and no study has been conducted among primary school children in Port Harcourt, Southern Nigeria. This study seeks to determine the prevalence of ADHD in primary school children in Port Harcourt. It is envisaged that findings from this study will assist to increase the overall awareness of ADHD and form a basis for health policy and planning.

\section{Materials and Methods}

This was a school - based descriptive cross sectional study. The study involved 884 pupils aged $4-18$ years who were selected from four primary schools in Port Harcourt metropolis, using a two - staged stratified sampling technique. Port Harcourt, the capital city of Rivers State, is located in the South-South geo-political zone of Nigeria. It is the nerve center of the oil industry in Nigeria. The urban nature of the area and oil exploration and production activities has caused a great influx of people from all over Rivers State and Nigeria. Its vegetation is that of an equatorial rain forest and mangrove swamp.

A structured questionnaire (Appendix I), the Vanderbilt ADHD Diagnostic Teacher Rating Scale[10] was administered by the classroom teacher of each child on the child. The Vanderbilt Rating Scales follow closely the criteria set forth in DSM-IV (Diagnostic and Statistical Manual - IV) and have been customized to observations made in the home and classroom environments. The questionnaire includes the 18 ADHD symptoms described in the DSM-IV, which are rated on a 4-point Likert scale (from 0 to 3) that indicates whether each ADHD symptom occurs never (score of 0 ), occasionally (score of 1), often (score of 2), or very often (score of 3). In addition to assessing ADHD symptoms, it includes a set of performance items that assess functional impairment. Teachers rate 8 partially overlapping, functional impairment items on a 5-point Likert scale (from 1 to 5) that indicates whether performance is excellent (score of 1), above average (score of 2), average (score of 3), somewhat problematic (score of 4), or problematic (score of 5) in each domain. To meet DSM-IV criteria for the diagnosis of ADHD, one must have at least 6 responses of "Often" or "Very Often" (scored 2 or 3 ) to either the 9 inattentive or 9 hyperactiveimpulsive items, or both and a score of 4 or 5 on any of the Performance items (36-43). To screen for co - morbidities like oppositional defiant disorder/conduct disorder one must have at least 3 responses of "Often" or "Very Often" on items 19-28 and a score of 4 or 5 on any of the Performance items (36-43) while to screen for anxiety/depression one must have at least 3 responses of "Often" or "Very Often" on items 2935 and a score of 4 or 5 on any of the Performance items 3643 (Appendix 1). Further interviews and assessment by Paediatric Neurologists were carried out on all children and their parents or guardians, who met the criteria for ADHD from the Vanderbilt ADHD Diagnostic Teacher Rating Scale. This was to confirm presence of symptoms, their onset and duration and make a diagnosis of ADHD and co morbidities when present. Diagnosis of ADHD was based on child having the required number of symptoms from the Vanderbilt ADHD Diagnostic Teacher Rating Scale, symptoms occurring in more than one setting, onset being before 7 years and symptoms lasting at least 6 months, and the Paediatric Neurologist's assessment.

In a study [11] that examined the psychometric properties of the Vanderbilt ADHD Diagnostic Teacher Rating Scale (VADTRS), for predictive validity, the VADTRS produced a sensitivity of 0.69 , specificity of 0.84 , positive predictive value of 0.32 , and negative predictive value of 0.96 when predicting future case definitions among children whose parents completed a diagnostic interview. The confirmation of the construct and convergent validity and acceptable scale reliabilities found in their study supports the utility of the VADTRS as a diagnostic rating scale for attention-deficit hyperactivity disorder. The low predictive validity demonstrates the need for multiple observers in establishing the diagnosis as was done in this study.

Data were entered into an Excel spread sheet and analyzed with Epi info version 7.1.2.

\section{Results}

A total of 884 pupils participated in the study consisting of $452(51.1 \%)$ males and $432(48.9 \%)$ females giving a male to female ratio of 1.01:1. The age of the pupils ranged from 4 to 18 years with a mean age of $10.02 \pm 2.83$ years and mode of 8 years. The mean age of the $10.08 \pm 2.87$ years for the females was higher than that of $9.97 \pm 2.80$ years for the males. The observed difference was not statistically significant $(\mathrm{t}=0.56, \mathrm{df}=1, \mathrm{p}=0.573)$. Table 1 shows the age group and gender distribution of the pupils. The ages of the children were grouped into two: younger children $4-9$ years and adolescents $10-18$ years of age. 
Table 1. Age group and gender distribution of respondents

\begin{tabular}{llll}
\hline $\begin{array}{l}\text { Age group } \\
\text { (years) }\end{array}$ & Gender & & \\
\cline { 2 - 4 } & Male N (\%) & Female N (\%) & Total N (\%) \\
\hline $4-9$ & $206(51.4)$ & $195(48.6)$ & $401(45.4)$ \\
$10-18$ & $246(50.9)$ & $237(49.1)$ & $483(54.6)$ \\
TOTAL & $452(51.1)$ & $432(48.9)$ & $884(100.0)$ \\
\hline
\end{tabular}

Out of the 884 pupils, $7(0.8 \%)$ had ADHD, out of which 6 $(85.7 \%)$ had the predominantly inattentive type, 2 (28.6\%) had the predominantly hyperactive-impulsive type and 1 $(14.3 \%)$ had the combined type. Four $(0.9 \%)$ out of 432 females compared to $3(0.7 \%)$ out of 452 males had ADHD. The difference was not statistically significant $\left(\chi^{2}=0.19\right.$, df $=1$, fisher exact $=0.475)$. Table 2 shows the relationship between subtypes of ADHD and gender. The only case of the combined subtype of ADHD was found in a female, hyperactive / impulsive subtype was shared equally between sexes and inattention subtype occurred more in females compared to males $(0.9 \%$ vs. $0.4 \%)$. There was no statistically significant difference between genders in the various subtypes. Six (1.2\%) out of the 483 pupils equal to or above 10 years of age had ADHD compared to $1(0.2 \%)$ out of the 401 pupils less than 10 years of age. The difference was not statistically significant $\left(\chi^{2}=2.75, \mathrm{df}=1, \mathrm{p}=0.098\right)$. The ages of the 7 pupils with ADHD were 9, 10, 11, 12, 13, 13 and 14 years.

Table 3 shows the relationship between ADHD, its subtypes and Oppositional \& Conduct Disorder. Oppositional \& Conduct disorders were found to be more prevalent in children with ADHD (42.9\% vs. $16.3 \%)$ and those with the Inattention subtype $(50.0 \%$ vs. $16.3 \%)$ than among other children. The differences observed were not statistically significant. Table 4 shows the relationship between ADHD, its subtypes and Anxiety / Depression. Anxiety / Depression were found to be more prevalent in children with ADHD (28.6\% vs. $10.5 \%)$ and all subtypes $(16.7 \%$ vs. $10.6 \%$ for Inattention subtype; $100.0 \% \quad$ vs. $10.4 \%$ for Hyperactive/Impulsive subtype; $100.0 \%$ vs. $10.5 \%$ for Combined subtype) than among other children. However, only the difference observed between those with the Hyperactive / Impulsive subtype and other children (100.0\% vs. $10.4 \%)$ was statistically significant $\left(\chi^{2}=16.85, \mathrm{df}=1, \mathrm{p}\right.$ $=0.011$ ).

Table 2. Relationship between ADHD subtype and gender

\begin{tabular}{|c|c|c|c|c|c|}
\hline ADHD Subtype & & Male N (\%) & Female N (\%) & Total N (\%) & Fisher \\
\hline \multirow{2}{*}{ Inattention } & Present & $2(0.4)$ & $4(0.9)$ & $6(0.7)$ & 0.322 \\
\hline & Absent & $450(99.6)$ & $428(99.1)$ & $878(99.3)$ & \\
\hline \multirow{2}{*}{ Hyperactive / Impulsive } & Present & $1(0.2)$ & $1(0.2)$ & $2(0.2)$ & 0.739 \\
\hline & Absent & $451(99.8)$ & $431(99.8)$ & $882(99.8)$ & \\
\hline \multirow{2}{*}{ Combined } & Present & $0(0.0)$ & $1(0.2)$ & $1(0.1)$ & 0.489 \\
\hline & Absent & $452(100.0)$ & $431(99.8)$ & 883 (99.9) & \\
\hline
\end{tabular}

Table 3. Relationship between ADHD, subtypes and Oppositional \& Conduct disorder

\begin{tabular}{|c|c|c|c|c|c|}
\hline \multirow[t]{2}{*}{ ADHD and Subtypes } & & \multicolumn{4}{|c|}{ Oppositional \& Conduct disorder } \\
\hline & & Present & Absent & Total & Fisher \\
\hline ADHD & Present & $3(42.9)$ & $4(57.1)$ & $7(0.8)$ & 0.093 \\
\hline \multirow{2}{*}{ Inattention } & Present & $3(50.0)$ & $3(50.0)$ & $6(0.7)$ & 0.06 \\
\hline & Absent & $143(16.3)$ & $735(83.7)$ & $878(99.3)$ & \\
\hline \multirow[t]{2}{*}{ Hyperactive / Impulsive } & Present & $0(0.0)$ & $2(100.0)$ & $2(0.2)$ & 0.697 \\
\hline & Absent & $146(16.6)$ & $736(83.4)$ & $882(99.8)$ & \\
\hline \multirow[t]{2}{*}{ Combined } & Present & $0(0.0)$ & $1(100.0)$ & $1(0.1)$ & 0.835 \\
\hline & Absent & $146(16.5)$ & $737(83.5)$ & $883(99.9)$ & \\
\hline
\end{tabular}

Table 4. Relationship between ADHD, subtypes and Anxiety / Depression

\begin{tabular}{|c|c|c|c|c|c|}
\hline \multirow[t]{2}{*}{ ADHD and Subtypes } & \multicolumn{5}{|c|}{ Anxiety / Depression } \\
\hline & & Present & Absent & Total & fisher \\
\hline \multirow{2}{*}{ ADHD } & Present & $2(28.6)$ & $5(71.4)$ & $7(0.8)$ & 0.165 \\
\hline & Absent & $92(10.5)$ & $785(89.5)$ & $877(99.2)$ & \\
\hline \multirow{2}{*}{ Inattention } & Present & $1(16.7)$ & $5(88.3)$ & $6(0.7)$ & 0.492 \\
\hline & Absent & $93(10.6)$ & $785(89.4)$ & $878(99.3)$ & \\
\hline \multirow{2}{*}{ Hyperactive / Impulsive } & Present & $2(100.0)$ & $0(0.0)$ & $2(0.2)$ & $0.011 *$ \\
\hline & Absent & $92(10.4)$ & $790(89.6)$ & $882(99.8)$ & \\
\hline \multirow{2}{*}{ Combined subtype } & Present & $1(100.0)$ & $0(0.0)$ & $1(0.1)$ & 0.106 \\
\hline & Absent & $93(10.5)$ & $790(89.5)$ & $883(99.9)$ & \\
\hline
\end{tabular}

* = significant 


\section{Discussion}

The prevalence of ADHD of $0.8 \%$ in this study is similar to the $0.5 \%$ reported among adolescents in New Zealand[12] and the $1.3 \%$ found among children in Russia.[13] The prevalence in this study is however markedly lower than that seen in various other studies conducted within[7,8] and outside[4,14-16] Nigeria. A review of the epidemiology and co - morbidities of ADHD among African children[17] showed that prevalence of ADHD varied with rates of between $5.4 \%$ and $8.7 \%$, amongst school children, $1.5 \%$ amongst children from the general population between $45.5 \%$ and $100.0 \%$ amongst special populations of children with possible organic brain pathology. A systematic review [4] and metaregression analysis on the other hand, showed prevalence rates ranging from $1-20 \%$ among school children and a worldwide-pooled prevalence of 5.29\% which was associated with significant variability. Factors that may be responsible for this wide range of variation noted among different studies include diagnostic criteria and tools used, source of information of children's behavior (parents or teachers), requirement of impairment for making a diagnosis of ADHD and geographic location of the studies. The diagnostic criteria, whether the DSM - III, DSM - IIIR or DSM - IV, used appear to influence estimated prevalence $[18,19]$.

The finding in this study of the most prevalent ADHD subtype being the predominantly inattentive subtype is similar to findings by Adewuya and Famuyiwa, [8] Pondé and Freire[14] and Ambuabunos et al. [7] It however differs from findings in other studies[20,21] where the combined subtype was found to be the most prevalent subtype. Ponde and Freire[14] used a teacher's rating scale as was done in the present study. It may be that teachers recognize symptoms of inattention more than parents since attention is required more in the classroom setting than in the home setting. This may account for the similarly high prevalence of the inattention subtype noticed in both studies.

The higher prevalence of ADHD in males that has been reported in other studies $[7,8,15,16,20]$ was not found in this study. There was a slightly higher prevalence in this study although not statistically significant. The higher prevalence of the inattentive subtype found in this study may account for the slight female preponderance observed since the inattentive subtype has been known to occur more commonly in females. [3] Furthermore, since girls in our culture are expected to be quieter, while boys are expected to be rowdier, perhaps the more severe cases are more easily identified by teachers in the gender in which this behavior is less expected, especially in the classroom setting. Earlier studies on the other hand, may have had a bias towards males as boys might be seen as the more prototypical ADHD child and therefore diagnosed with ADHD more readily than girls.
[22]

It is known that the rates of ADHD decrease with increasing age [3] but this was not evident in this study where a higher prevalence was found in children above 10 years of age. The finding however, was not statistically significant and may be incidental. It is worthy to note however, that compulsory basic education is not completely enforced in our Country. A difficult hyperactive child may therefore be kept at home and not sent to school, especially when they are younger and their symptoms more overt. This may contribute to the low prevalence seen among the younger age group in this study. Some other studies [7, 16, 21] also noted a different pattern with prevalence of ADHD symptoms being highest at about $9-11$ years.

Children with ADHD show significant co-morbidity with other psychiatric disorders.[3] Commonly encountered comorbid conditions include Oppositional Defiant Disorder (ODD), Conduct Disorder (CD), Mood and Anxiety Disorders, Learning and Language Disorders as well as Tic Disorders.[3] The present study showed that Oppositional \& Conduct disorders as well as Anxiety \& Depressive disorders were higher in children with ADHD as seen in other studies.[8,16,17,20,23] In a review of the epidemiology and co-morbidities ADHD among African children, Bakare[17] noted that the most commonly reported co-morbid conditions associated with ADHD among African children were Oppositional Defiant Disorder (ODD) and Conduct Disorder. Eapen et al [23] noted significant association of ADHD with a number of psychiatric disorders ranging from anxiety and depression, to delinquency and aggression among children in the United Arab Emirates.

\section{Conclusion}

This study acknowledges that ADHD occurs in children in Southern Nigeria as it occurs in other areas around the world, although the prevalence rates may vary between regions. ADHD is also associated with other psychiatric comorbidities.

\section{Ethical Consideration}

Ethical clearance was obtained from the University of Port Harcourt Teaching Hospital's Ethics Committee. Permission was obtained from the Rivers State Ministry of Education and the Head teachers of the index schools. Informed consent was obtained from the parents / guardians and classroom teachers of the pupils. The parents and or guardians of those with ADHD were counseled and follow up sessions were planned and conducted in the University of Port Harcourt Teaching Hospital. 


\section{Appendix 1}

Chiropractic Neurology Center

Vanderbilt Assessment Scale-Teacher Informant

Name of student:

Gender:

Age: Grade:

Date:

Completed by: Teacher's Phone Number:

Directions: Each rating should be considered in the context of what is appropriate for the age of the child and should reflect that child's behavior since the beginning of the school year. Please indicate the number of weeks or months you have been able to evaluate the behaviors:

Is this evaluation based on a time the child _ was on medication _ was not on medication _ not sure?

\begin{tabular}{|c|c|c|c|c|c|}
\hline \multicolumn{2}{|c|}{ Symptoms } & \multirow{2}{*}{$\begin{array}{c}\text { Never } \\
0\end{array}$} & \multirow{2}{*}{$\begin{array}{c}\text { Occasionally } \\
1\end{array}$} & \multirow{2}{*}{$\begin{array}{c}\text { Often } \\
2\end{array}$} & \multirow{2}{*}{$\begin{array}{c}\begin{array}{c}\text { Very } \\
\text { Often }\end{array} \\
3\end{array}$} \\
\hline 1. & Fails to give attention to details or makes careless mistakes in schoolwork & & & & \\
\hline 2. & Has difficulty sustaining attention to tasks or activities & 0 & 1 & 2 & 3 \\
\hline 3. & Does not seem to listen when spoken to directly & 0 & 1 & 2 & 3 \\
\hline 4. & $\begin{array}{l}\text { Does not follow through on instructions and fails to finish schoolwork (not due to refusal or } \\
\text { failure to understand) }\end{array}$ & 0 & 1 & 2 & 3 \\
\hline 5. & Has difficulty organizing tasks and activities & 0 & 1 & 2 & 3 \\
\hline 6. & Avoids, dislikes, or is reluctant to engage in tasks that require sustained mental effort & 0 & 1 & 2 & 3 \\
\hline 7. & Loses things necessary for tasks or activities (e.g., toys, school assignments, pencils, or books) & 0 & 1 & 2 & 3 \\
\hline 8. & Is easily distracted by noises or other stimuli & 0 & 1 & 2 & 3 \\
\hline 9. & Is forgetful in daily activities & 0 & 1 & 2 & 3 \\
\hline 10. & Fidgets with hands or feet or squirms in seat & 0 & 1 & 2 & 3 \\
\hline 11. & Leaves seat in classroom or in other situations in which remaining seated is expected & 0 & 1 & 2 & 3 \\
\hline 12. & Runs about or climbs excessively in situations in which remaining seated is expected & 0 & 1 & 2 & 3 \\
\hline 13. & Has difficulty playing or engaging in leisure activities quietly & 0 & 1 & 2 & 3 \\
\hline 14. & Is "on the go" or often acts as if "driven by a motor" & 0 & 1 & 2 & 3 \\
\hline 15. & Talks excessively & 0 & 1 & 2 & 3 \\
\hline 16. & Blurts out answers before questions have been completed & 0 & 1 & 2 & 3 \\
\hline 17. & Has difficulty waiting in line & 0 & 1 & 2 & 3 \\
\hline 18. & Interrupts or intrudes on others (eg, butts into conversations/games) & 0 & 1 & 2 & 3 \\
\hline 19. & Loses temper & 0 & 1 & 2 & 3 \\
\hline 20. & Actively defies or refuses to comply with adults' requests or rules & 0 & 1 & 2 & 3 \\
\hline 21. & Is angry or resentful & 0 & 1 & 2 & 3 \\
\hline 22. & Is spiteful and vindictive & 0 & 1 & 2 & 3 \\
\hline 23. & Bullies, threatens, or intimidates others & 0 & 1 & 2 & 3 \\
\hline 24. & Initiates physical fights & 0 & 1 & 2 & 3 \\
\hline 25. & Lies to obtain goods for favors or to avoid obligations (eg, "cons" others) & 0 & 1 & 2 & 3 \\
\hline 26. & Is physically cruel to people & 0 & 1 & 2 & 3 \\
\hline 27. & Has stolen items of nontrivial value & 0 & 1 & 2 & 3 \\
\hline 28. & Deliberately destroys others' property & 0 & 1 & 2 & 3 \\
\hline 29. & Is fearful, anxious, or worried & 0 & 1 & 2 & 3 \\
\hline 30. & Is self-conscious or easily embarrassed & 0 & 1 & 2 & 3 \\
\hline 31. & Is afraid to try new things for fear of making mistakes & 0 & 1 & 2 & 3 \\
\hline 32. & Feels worthless or inferior & 0 & 1 & 2 & 3 \\
\hline 33. & Blames self for problems; feels guilty & 0 & 1 & 2 & 3 \\
\hline 34. & Feels lonely, unwanted, or unloved; compains that "no one loves him or her" & 0 & 1 & 2 & 3 \\
\hline
\end{tabular}




\begin{tabular}{|c|c|c|c|c|c|c|c|c|}
\hline \multicolumn{5}{|c|}{ Symptoms } & \multirow{2}{*}{$\begin{array}{c}\text { Never } \\
0\end{array}$} & \multirow{2}{*}{\begin{tabular}{|c|} 
Occasionally \\
1
\end{tabular}} & \multirow{2}{*}{$\begin{array}{c}\text { Often } \\
2\end{array}$} & \multirow{2}{*}{$\begin{array}{c}\begin{array}{r}\text { Very } \\
\text { Often }\end{array} \\
3\end{array}$} \\
\hline \multirow[t]{2}{*}{35.} & \multicolumn{4}{|l|}{ Is sad, unhappy, or depressed } & & & & \\
\hline & Performance Academic Performance & Excellent & Above Average & Average & Somew & lat of a Problem & Pro & blematic \\
\hline 36. & Reading & 1 & 2 & 3 & & 4 & & 5 \\
\hline 37. & Mathematics & 1 & 2 & 3 & & 4 & & 5 \\
\hline 38. & Written expression & 1 & 2 & 3 & & 4 & & 5 \\
\hline . & Classroom Behavioral Performance & Excellent & Above Average & Average & Somew & lat of a Problem & Pro & blematic \\
\hline 39. & Relationship with peers & 1 & 2 & 3 & & 4 & & 5 \\
\hline 40. & Following directions & 1 & 2 & 3 & & 4 & & 5 \\
\hline 41. & Disrupting class & 1 & 2 & 3 & & 4 & & 5 \\
\hline 42. & Assignment completion & 1 & 2 & 3 & & 4 & & 5 \\
\hline 43. & Organizational skills & 1 & 2 & 3 & & 4 & & 5 \\
\hline
\end{tabular}

Comments:

\section{For Office Use Only}

Total number of items scored 2 or 3 in items 1-9:

Total number of items scored 2 or 3 in items 10-18:

Total number of items scored 2 or 3 for items 1-18:

Total number of items scored 2 or 3 in items 19-28:

Total number of items scored 2 or 3 in items 29-35:

Total number of items scored 2 or 3 in items 36-43:

(ADHD, predominantly inattentive type - 6 or more symptoms)

(ADHD, predominantly hyperactive-impulsive type-6 or more symptoms)

(ADHD, combined type - 6 or more symptoms of both types)

(oppositional and conduct disorder screen -3 or more symptoms)

(anxiety/depression screen-3 or more symptoms)

(academic and classroom behavior symptoms)

\section{Scoring Instructions for the Vanderbilt Assessment Scale-Teacher Informant}

The Vanderbilt Assessment Scale has two components: symptom assessment and impairment of performance.

For the ADHD screen, the symptoms assessment component screens for symptoms that meet the criteria for both inattentive (items 1-9) and hyperactiveimpulsive ADHD (items 10-18). To meet DSM-IV criteria for the diagnosis of ADHD, one must have at least 6 responses of "Often" or "Very Often" (scored 2 or 3 ) to either the 9 inattentive or 9 hyperactive-impulsive items, or both and a score of 4 or 5 on any of the Performance items (36-43). There is a place to record the number of symptoms that meet this criteria in each subgroup.

The Vanderbilt Assessment Scale also contains items that screen for 3 other co-morbidities: oppositional defiant disorder (items 19-22), conduct disorder (items 23-28), and anxiety/depression (items29-35).

To screen for oppositional defiant disorder/conduct disorder one must have at least 3 responses of "Often" or "Very Often" on items 19-28 and a score of 4 or 5 on any of the Performance items (36-43).

To screen for anxiety/depression one must have at least 3 responses of "Often" or "Very Often" on items 29-35 and a score of 4 or 5 on any of the Performance items 36-43.

The Vanderbilt Assessment Scale should NOT be used alone to make a diagnosis. The practitioner must consider information from other sources and may ask for the child's report cards, samples of the child's schoolwork, as well as any psychometric testing done.

Adapted from the Vanderbilt Rating Scales developed by Mark L. Wolraich, MD. Revised-1102. For additional information about this scale see: Wolraich, M. L., et al. (1998) Obtaining systematic teacher reports of disruptive behavior disorders utilizing DSM-IV. (Diagnostic and Statistical Manual of Mental Disorders, 4th ed.) Journal of Abnormal Child Psychology. Or visit the following website: http://www.findarticles.com/cf_dls/m0902/n2_v26/20824364/p9/article.jhtml?term= This form may be copied by active myADHD.com subscribers. Copyright (C) 2003 Health Link Systems, Inc. MyADHD.com

\section{References}

[1] American Psychiatric Association: Diagnostic and Statistical Manual of Mental Disorders, 4th edition. Arlington, VA., American Psychiatric Association, 2000.

[2] American Psychiatric Association: Diagnostic and Statistical Manual of Mental Disorders, 5th edition. Arlington, VA., American Psychiatric Association, 2013.

[3] Cunningham NR, Jensen P. Attention-deficit/Hyperactivity Disorder. In: Kliegman RM, Behrman RE, Jenson HB, Stanton BF editors. Nelson Textbook of Pediatrics, 19th ed. Philadelphia: Saunders Elsevier; 2011. p.108 - 111.
[4] Polanczyk G, de Lima MS, Horta BL, Biederman J, Rohde LA. The worldwide prevalence of ADHD: a systematic review and metaregression analysis. Am J Psychiatry. 2007; 164(6):942948.

[5] Polanczyk GV, Willcutt EG, Salum GA, Kieling C, Rohde LA. ADHD prevalence estimates across three decades: an updated systematic review and meta-regression analysis. Int. J. Epidemiol. (2014) 43 (2): 434-442.

[6] Willcutt EG. The Prevalence of DSM-IV AttentionDeficit/Hyperactivity Disorder: A Meta-Analytic Review. Neurotherapeutics. Jul 2012; 9(3): 490-499.

[7] Ambuabunos E A, Ofovwe E G, Ibadin M O. Community survey of attention-deficit / hyperactivity disorder among primary school pupils in Benin City, Nigeria. Ann Afr Med 
2011; 10: 91-6.

[8] Adewuya AO, Famuyiwa OO. Attention deficit hyperactivity disorder among Nigerian primary school children: prevalence and co-morbid conditions. Eur Child Adolesc Psychiatry. 2007 Feb; 16(1): 10-5.

[9] Moina BS, Pelham WE, Gnagy EM, Thompson AL, Marshal MP. Attention Deficit Hyperactivity Disorder risk for heavy drinking and alcohol use disorder is age specific. Alcohol Clin Exp Res 2007; 31(4): 643-54.

[10] Wolraich ML, Feurer ID, Hannah JN, Pinnock TY, Baumgaertel A. 1998. Obtaining systematic teacher reports of disruptive behavior disorders utilizing DSM-IV. Journal of Abnormal Child Psychology 26(2):141-152.

[11] Wolraich ML1, Bard DE, Neas B, Doffing M, Beck L. The psychometric properties of the Vanderbilt attention-deficit hyperactivity disorder diagnostic teacher rating scale in a community population. J Dev Behav Pediatr. 2013 Feb; 34(2): 83-93.

[12] Schaughency E, McGee R, Raja SN, Feehan M, Silva PA. Self-reported inattention, impulsivity, and hyperactivity at ages 15 and 18 years in the general population. J Am Acad Child Adolesc Psychiatry. 1994; 33: 173-184.

[13] Goodman R, Slobodskaya H, Knyazev G: Russian child mental health: a cross-sectional study of prevalence and risk factors. Eur Child Adolesc Psychiatry 2005; 14:28-33.

[14] Pondé MP, Freire ACC. Prevalence of attention deficit hyperactivity disorder in schoolchildren in the city of Salvador, Bahia, Brazil. Arq. Neuro-Psiquiatr. 2007; 65(2A): 240 - 244.

[15] Juneja M, Sairam S, Jain R. Attention Deficit Hyperactivity Disorder in Adolescent School Children. Indian Pediatr 2014;51: 151-152.
[16] Venkata JA, Panicker AS. Prevalence of attention deficit hyperactivity disorder in primary school children. Indian J Psychiatry 2013; 55: 338-42.

[17] Bakare MO. Attention deficit hyperactivity symptoms and disorder (ADHD) among African children: a review of epidemiology and co-morbidities. Afr J Psychiatry. 2012; 15:358-361.

[18] Brown RT, Freeman WS, Perrin JM, et al. Prevalence and assessment of attention-deficit/hyperactivity disorder in primary care settings. Pediatrics 2001; 107: E43.

[19] Graetz BW, Sawyer MG, Baghurst P. Gender differences among children with DSM-IV ADHD in Australia. J Amer Acad Child Adolesc Psychiatry 2005; 44: 159-168.

[20] Souza I, Pinheiro MA, Denardin D, Mattos P, Rohde LA. Attention-Deficit/Hyperactivity Disorder and comorbidity in Brazil Comparisons between two referred samples. Eur Child Adolesc Psychiatry. 2004; 13:243-248.

[21] Al Hamed JH, Taha AZ, Sabra AA, Bella H. Attention Deficit Hyperactivity Disorder (ADHD) among Male Primary School Children in Dammam, Saudi Arabia: Prevalence and Associated Factors. J Egypt Public Health Assoc. 2008; 83(3 \& 4): $165-182$.

[22] Walker S, Venter A, Van der Walt A, Esterhuyse KGF. Prevalence of attention-deficit/hyperactivity disorder (ADHD) symptomatology and psychiatric co-morbidity among adolescents diagnosed with ADHD in childhood. South African Journal of Psychiatry. 2011;17(1):24-28.

[23] Eapen V, Mabrouk AA, Zoubeidi T, Sabri S, Yousef S, AlKetbi $\mathrm{J}$ et al. Epidemiological Study of Attention Deficit Hyperactivity Disorder Among School Children in the United Arab Emirates. Journal of Medical Sciences. 2009; 2(3): 119127 